\title{
The need for ESP in Burundi: What do tertiary English teachers say sbout it?
}

\author{
Arcade Nduwimana \\ Ecole Normale Supérieure du Burundi
}

\begin{abstract}
This study examines the views that tertiary English teachers hold on the need for English for Specific Purposes (ESP) in Burundi higher education. To do so, it investigates the extent to which they are familiar with the theory and practice of ESP. For this study, 32 English teachers were contacted to participate in it. They were all requested to complete an online questionnaire, but only 17 proved willing to do so. The findings revealed that the majority of teachers are familiar with the practice of ESP. Although many of them reported to have high familiarity with the field of ESP, a few of them conduct a Needs Analysis (NA) before teaching ESP courses. Results also indicated that tertiary English teachers highly acknowledge the importance of teaching ESP in Burundi higher Education and, therefore, would encourage the ministry of education to fund an ESP project.
\end{abstract}

Keywords: ESP, Burundi higher education, online questionnaire, NA

\section{Introduction}

The demand for English language is growing across the globe and so its use in higher education. This increasing demand for English is translated into, for example, the growing number of non-English speaking countries that are switching from French to English or adopting English as an official language such as Gabon, Burundi, South Sudan ( Plonski, Teferra \& Brady, 2013), and others adopting English as medium of instruction in higher education (Dearden, 2018 ).
In Burundi where French is a medium of instruction, the English language was adopted as an official language in 2014 ( Uwimana, 2014). This change of the status of English language resulted from the growing interest in and need for English that Burundians have shown in the last three decades. Indeed, Nizonkiza (2006) argues that the interest in English is growing considerably. The evidence for this is that the number of people enrolling in English language programmes increased tremendously throughout the decade of 1996 to 2005 (ibid). Currently, English is 
taught from primary to tertiary level of education. At tertiary level, even departments/branches other than English (DBOE) have an English course on their curricula. Besides, some universities are now offering English Medium Instruction. The primary reason for this shift in the medium of instruction is a desire for universities to internationalise both by attracting international students and by ensuring that domestic students are advantaged on the global job market (Dearden, 2018).

Given this situation, it seems reasonable to ask such questions: (1) what kind of English are French Medium universities offering to their students? (2) Do the pre-studies English courses offered by English-Medium Universities enable students to meet the language requirements to undertake their studies in English? (3) Are teachers well prepared to teach English courses in those universities? This small-scale study has no space to answer these questions but the point is that the above-mentioned students have specific needs in English. These needs range from vocational, to professional and to academic (Bracaj, 2014; Charles, 2013; Thompson, 2013; as cited in Çelik, Stavicka \& Odina, 2018). It follows that; though some may disagree, there is a need in these universities to teach English for Specific purposes (ESP), a major subfield of English Language Teaching (ELT), which aims to meet the students 'specific needs within a particular discipline (Sabieh, 2018; DudleyEvans \& St John,1998). However, the extent to which tertiary English teachers in Burundi are familiar with the theory and practice of ESP is so far still questionable. Besides the views these teachers hold on the need for ESP in Burundi higher Education are not known.

\section{Literature review}

\section{What is ESP?}

The acronym ESP is used as an umbrella term to refer to the teaching of English for all specific purposes such as academic, occupational or professional purposes(Basturkmen,2017).Hutchinson and Waters (1988) define ESP as an approach to language teaching in which all decisions as to content and methodology are based on the learner's reason for learning [emphasis is added]. What those who adopt ESP approach consider as distinguishing it from other approaches to ELT is the commitment to the goal of providing language instruction that addresses students' own specific language learning purposes (Hyland, 2002; as cited in Belcher, 2009).

Dudley-Evans and St John (1998) provide another definition of ESP that is rather more comprehensive. Drawing on Stevens' (1988) definition of ESP, they base their definition on the distinction between absolute and variable characteristics. They identified three absolute characteristics: (1)ESP is designed to meet specific needs of the learner; (2)ESP makes use of the underlying methodology and activities of the discipline it serves; and (3) ESP is centred on the language (grammar, lexis, register), skills, discourse and genres appropriate to these activities. The same authors suggested four variable (optional) characteristics of ESP: (1) ESP may be related to or designed for specific discipline. (2) ESP may use, in specific teaching situations, a different methodology from that of general English. (3) ESP is likely to be designed for adult learners, either at a tertiary level institution or in a professional work situation; it could, however, be used 
for learners at secondary school level. (4) ESP is generally designed for intermediate or advanced students; most ESP courses assume basic knowledge of the language system, but it can be used with beginners.

Although the literature on ESP provide a number of definitions, they all agree that ESP is centred on learner's reasons for learning, that is, their needs for taking the course. Therefore, Needs Analysis (NA) is the cornerstone of any ESP course (Brown, 2016; Rahman, 2015; Basturkmen 2010).

\section{Growing demand for ESP worldwide}

Since its emergence in the 1960 s as a distinctive movement within the field of ELT, ESP has grown rapidly and is still spreading worldwide. This is mainly due to the status of English language as an "international language or a global lingua franca" (Marlina \& Xu, 2018). Indeed, English language is, nowadays, predominantly used in diverse international economic and cultural arenas, and in electronic communication (ibid). Similarly, English continues to be the dominant language in business, technology, media, education, medicine, and research, and therefore, the demand for ESP is rapidly growing to fulfil people with an instrumental purpose (Tsao, 2008; Xu, 2008, as cited in Lin\& Huang).

To respond to the growing demand for ESP, some countries such as Brazil, Tunisia, Algeria etc. did set up ESP projects (Labassi, 2010; Bouyakoub \& Bouyacoub, 2017). In Saudi Arabia, for example, Ahmad (2012) argues that the demand for ESP is high. Being in line with Ahmad, Alsubaie (2016) calls for the establishment of a local ESP Saudi Center and argues that the Brazilian
ESP experience is applicable to Saudi situation.

\section{Motivation for the study}

To conduct this study, the researcher was motivated by a combination of three factors. The first factor is the researcher's experience as an English teacher at a tertiary level. Hewas assigned to teach English to Engineering students. Because of lack of teaching materials at the institution and the short time given to prepare the course, he could not design his own course that would cater for the specific needs of the learners. He therefore resorted to ready-made materials and decided to use Glendinning's and Glendinning's (1995) 'Oxford English for Electrical and Mechanical Engineering' textbook. Although the textbook seemed to reflect their discipline, it turned out that students were not motived. The textbook proved difficult due to student's low level of English and of engineering subjects.

As far as the second factor is concerned, a student studying in Management and Public Finance at a National Administration School, requested help from the researcher - explaininga handout provide by an English course teacher. Surprisingly, the handout was nothing but a list of simply explained (only the first meaning in the dictionary was given) vocabulary items without examples. This raised the question, on the part of the researcher, of whether the English course teacher had conducted a Needs Analysis to determine whether the handout would cater for the particular needs of the students.

The last factor that motivated this study is the growing number of English-medium universities. At these universities, students are given pre-studies English courses to enable them follow their studies 
successfully in English. It is, however, questionable whether these courses are tailor-made to serve the specific academic language needs of the students.

\section{Research questions}

The following two research questions were the main concern of this study:

1. To what extent are tertiary English teachers in Burundi familiar with the theory and practice of ESP?

2. What views do they hold on the need for ESP in Burundi higher education?

\section{Methodology}

\section{Participants}

The subjects in this study are tertiary English teachers from two public higher institutions namely University of Burundi (UB) and Ecole Normale Supérieure (ENS). These subjects were chosen because they are more exposed to the teaching of English in academic settings and are very often, if not always, called upon to teach English courses to non-English major (NEM) university students.

The link to the questionnaire was sent to 32 tertiary English teachers via email. Of the 32 English teachers that received the online questionnaire, only 17 were willing to respond to it. Of the 17 teachers who responded to the questionnaire, $58.8 \%$ work at ENS while $41.2 \%$ teach at UB. Besides, $70.6 \%$ are male whereas $29.4 \%$ are female. Their teaching experience ranges from 2 to 38 years.

\section{Research instrument}

This study used an online questionnaire that consiwrite sted of 16 items grouped into two sections. The first section (item 1 to 7) aimed at gathering data as to how tertiary English teachers are familiar with the theory and practice of ESP. The second section (item 8 to 16) was devised to collect data about the teachers' views on the need for ESP in Burundi. Of all the 16 items, only two were open-ended questions. All the remaining 14 items were put on rating scales ranging from 2 to 5 points.

\section{Data collection procedures}

As the instrument used was the online questionnaire, participants were contacted via e-mail. Their mail addresses were gathered from the heads of English departments at UB and ENS. Since the targeted population was not too large, all that could be reached were requested to take part in this study. They were given a month to complete the questionnaire.

\section{Findings}

\section{Findings for the first research question}

Regarding the teachers' familiarity with the theory and practice of ESP, $82.4 \%$ of the respondents reported that they had taught in DBOE (see Graph1); while 64.7\% confirmed that they had taught English course in language centres (see Graph 2). Besides, $70.6 \%$ of the respondents reported that they had, at least once, taught English to a group of learners who have special and/ or immediate needs for English ( e.g. : company workers, civil servants, businessmen, diplomates etc.) (See Graph 3).From this, it can be seen that tertiary English teachers have practiced the teaching of ESP, though the quality of their practice is not known. 
Graph 1: Teaching ESP in Departments/Branches Other than English

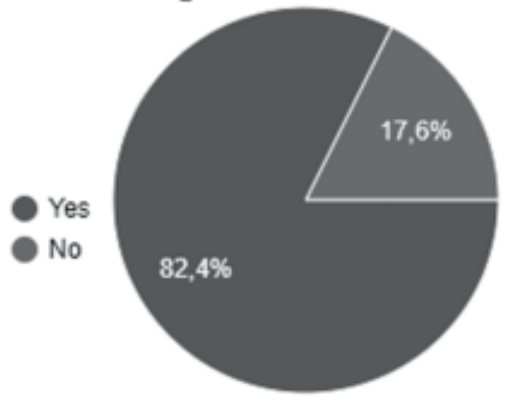

Graph 2: Teaching ESP in Language Centres

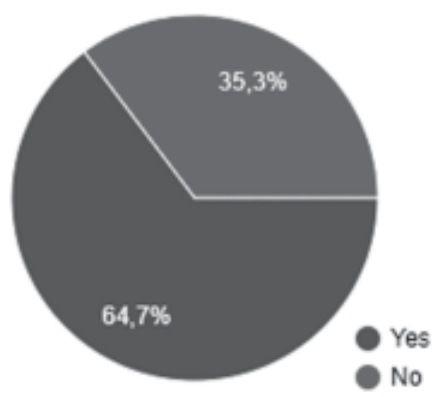

Graph 3: Teaching English to a group of learners who have special and/ or immediate needs for

English

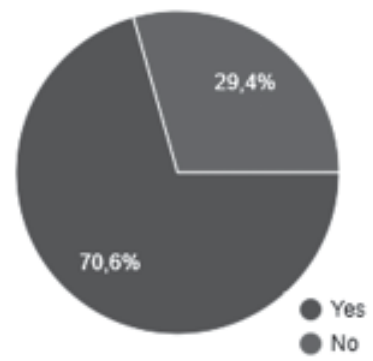

Although many of the tertiary English teachers reported to have already taught in DBOE and/or in language centres, the results on Graph 4 show that a few of them (47.1\%) conducted a Needs Analysis before teaching the course. However, all the respondents (100 $\%$ ) agree that it is necessary to conduct NA before teaching ESP courses (see Graph 5).
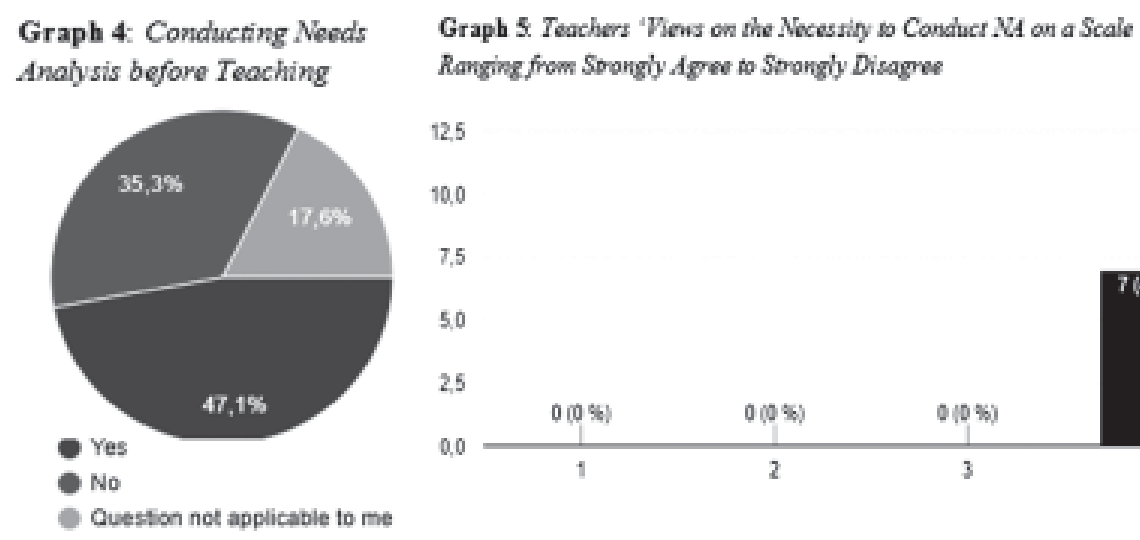

10,0

7,5

5.0

2,5

0,0

000

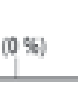

$0(0 \%)$
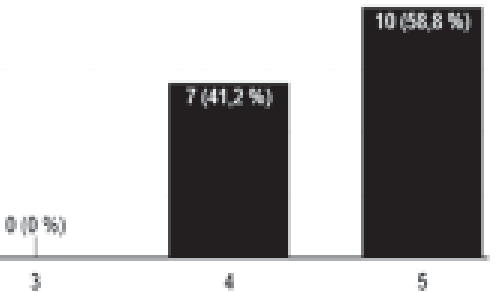

Asked to rate their knowledge in the field of NA on scale ranging from poor to excellent, only $47.1 \%$ rated themselves as having very good knowledge whereas $29.4 \%$ reported to have good knowledge, and $23.5 \%$ to have fair knowledge (see Graph 6). This indicates that there is a need for tertiary English teachers to expand their knowledge in NA. Similarly, asked to rate, on the whole, their familiarity with the theory in the field of ESP, $52.9 \%$ of the respondents said that they have high familiarity with the field of ESP; $23.5 \%$ reported to have medium familiarity, while $17.6 \%$ confirmed to be poorly familiar with ESP (See Graph 7).

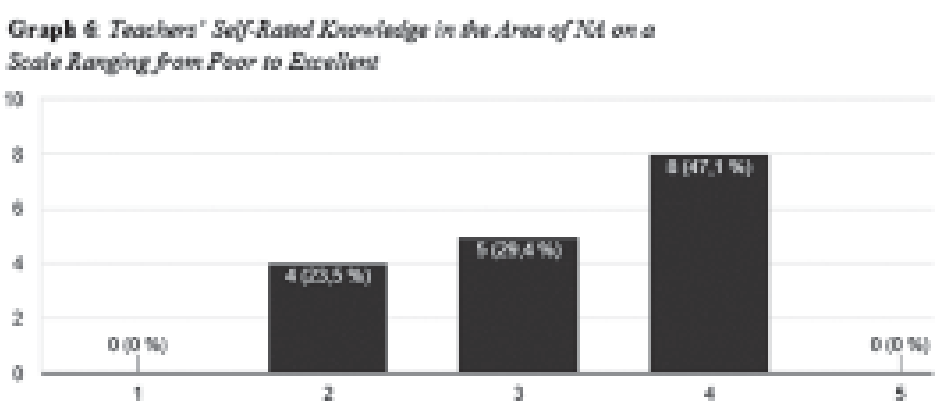




\section{Graph 7: Teachers' Self-rated Familiarity with the Field of ESP on a Scale Ranging from Low to Very High}

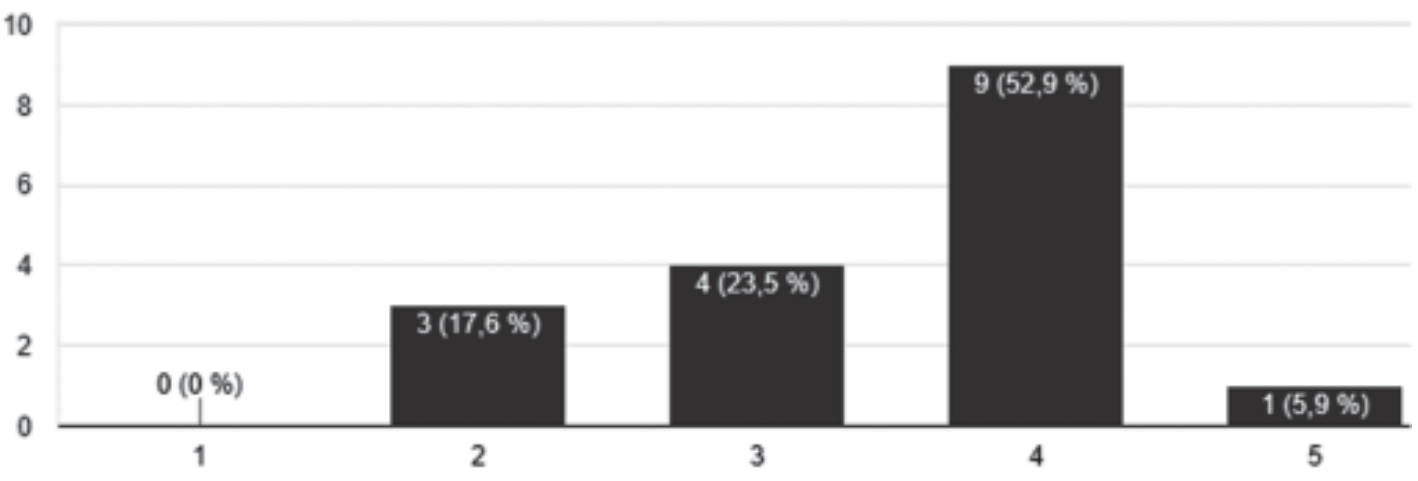

\section{Findings for the Second Research Question}

Graph 8: Teachers' Views on the Importance of English Course
in Departments/ Branches other than English

As far as teacher's views on the need for ESP in Burundi higher education are concerned, $58.8 \%$ of the respondents believe that it is very important to teach English to NEM students, and $29.4 \%$ believe that it is extremely important (See Graph 8). This shows that teachers have a positive view about the teaching of English to NEM students

Regarding the reasons for the need of English course in DBOE, respondents were asked to show their level of agreement on a rating scale ranging from strongly disagree to strongly agree. The findings on Table 1 show that the majority of tertiary English teachers (88.8\%) strongly agree that there is a need for English course in DBOE to help NEM students to get access to academic and scientific sources published in English. Similarly, teachers believe that studying English in DBOE increases the chance to get a scholarship to study abroad. In fact, $64.7 \%$ strongly agree on this while $29.4 \%$ agree. Although $17.6 \%$

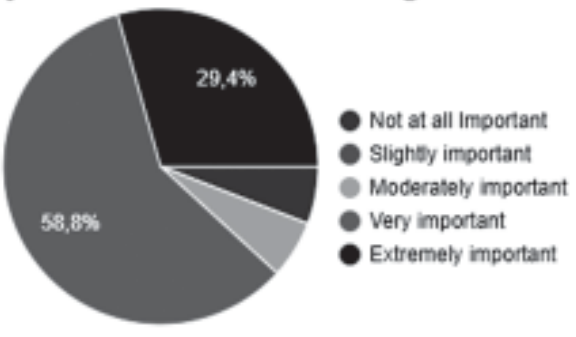

of the respondents are neutral on whether the English course help NEM students to get a high quality job after graduation; $35.3 \%$ strongly agree about it, whereas 33.3\% agree. In nutshell, tertiary English teachers perceive the need for teaching English in DBOE.

Table 1. Teachers' Views on the Reasons for the Need to Study English in DBOE 


\begin{tabular}{|c|c|c|c|c|c|c|}
\hline Reasons & 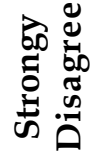 & 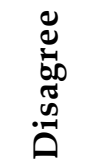 & 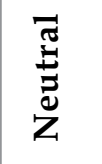 & 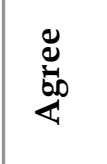 & 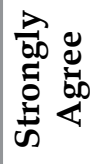 & 䒕 \\
\hline 1. To get high quality job after graduation & $5.9 \%$ & $5.9 \%$ & $17.6 \%$ & $33.3 \%$ & $35.3 \%$ & $100 \%$ \\
\hline $\begin{array}{l}\text { 2. To increase chance to get a scholarship } \\
\text { to study abroad }\end{array}$ & $0 \%$ & $5.9 \%$ & $0 \%$ & $29.4 \%$ & $64.7 \%$ & $100 \%$ \\
\hline $\begin{array}{l}\text { 3. To get access to academic and } \\
\text { scientific sources published in English }\end{array}$ & $0 \%$ & $0 \%$ & $0 \%$ & $11.8 \%$ & $88.2 \%$ & $100 \%$ \\
\hline
\end{tabular}

The other main reasons for the need to study English in DBOE, as was provided by participants in an open-ended way, are listed on Table 2

Table 2. Other Main Reasons Outlined by Teachers for the Need for English in DBOE

- To pass international English tests,

- To establish business and scientific contact with people from English speaking countries,

- To attend conferences held in English, etc.,

- To enhance intercultural communication,

- Because English opens students to the world,

- To easily integrate in native English speaker communities; understand their cultures through readings, movies, etc.

- Meet different requirements and needs of globalisation in this fastchanging world,

- Because it is a great asset for research, many publications are in English.
Asked about what kind of English that should be taught to NEM students, $70.6 \%$ of the teachers suggested that students should be taught both academic and vocational English (see Graph 9). Similarly, $87,5 \%$ highlighted that they would highly encourage the Ministry of Higher Educations and Scientific Research to fund an ESP project (see Graph11).

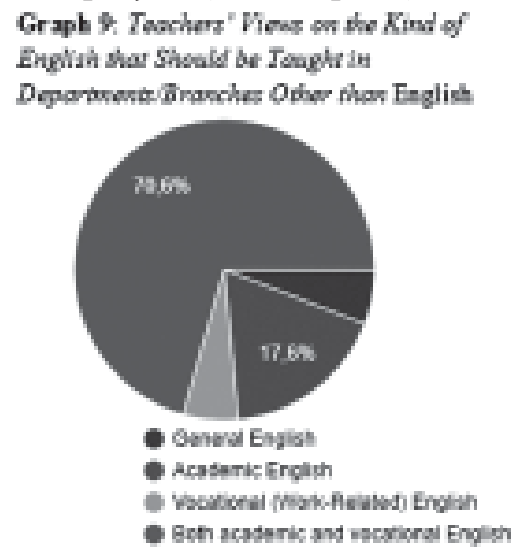

Graph 10: Teachers' Vieus abous Funding on ESP Project in Burnati Higher Edwation

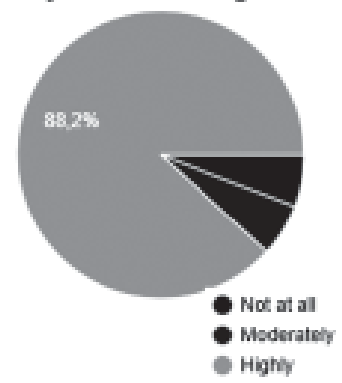


Asked to explain why the Ministry of Higher Education and Scientific Research should fund an ESP project, respondents stated the following, as summarised on Table 3.

\section{Table 3.Reasons for Funding an ESP Project in Higher Education}

- ESP curriculum design and implementation requires means and resources which transcend those available for the teaching of General English.

- ESP is very important; it meets the English language needs of students not majoring in English studies.

- Since the need for Burundians to use English remains tremendous (in businesses, studies, transport, etc.), the ministry should sustain each initiative related to promoting ESP to help learners of ESP succeed.

- English is a world language and therefore it is essential that specialists in other domains have a mastery of it to help them communicate across the borders.

- ESP project will help detect the specific English language needs for every branch or department and design tailored curricula that will efficiently meet the students' needs.

Regarding the contents of different programs taught in specific branches, there has been, so far, individual initiatives from teachers. It is therefore high time there were a basic program for each field (agriculture, computer science, physics and technology, justice, health, etc.)

\section{Discussion and implications of the Findings}

\section{Teachers' Familiarity with the theory and practice of ESP}

The results obtained from the online questionnaire revealed that the majority of teachers have, at least once, taught English course in departments other than English $(81.3 \%)$ or in language centres $(62.5 \%)$. Although many of the participants rated themselves as having a good knowledge in the field of NA, only a few of them (43.8 $\%$ ) admitted to have conducted a Needs Analysis before teaching the course. In such a situation, it seems reasonable to ask the question of whether the language needs of NEM students are served. Indeed, Needs Analysis is acknowledged as the mostimportant part in any course development (Brown, 2016; Basturkmen, 2010 , etc.). It is the key stage in ESP (Rahman, 2015).

Another finding regarding teachers' familiarity with ESP is that $50 \%$ admitted to have a high familiarity with ESP. Since only a few of them conduct a NA before teaching, one may ask the question as put by Çelik, Stavicka, and Odina (2018): 'Are we really teaching English for specific purposes, or basic English skills?'

\section{Teachers' views on the need for ESP in Burundi higher Eeducation}

The analysis of the data from the online questionnaire showed that $58.8 \%$ of the respondents asserted that it is very important that DBOE have an English course on their curricula; $29.4 \%$ highlighted that it is extremely important. According to teachers $(87.5 \%)$, the main reason for this need of ESP in DBOE is that students 
will get access to academic and scientific sources published in English. These findings are consistent with the Brazilian and Tunisian ESP projects which assigned priority to the reading skill so that ESP students can read field literature which is, in some disciplines, available exclusively in English (Labassi, 2010). The findings also indicated that $70.6 \%$ of the respondents suggested that NEM students be taught both academic and vocation English. Indeed, ESP students' needs range from vocational, to professional and to academic (Bracaj, 2014; Charles, 2013; Thompson 2013; as cited in Çelik, Stavicka \& Odina, 2018). The respondents $(87.5 \%)$ also highlighted that they would highly encourage the Ministry of Higher Education and Scientific Research in Burundi to fund an ESP project.

\section{Implications of the findings}

The results of this study have implications for potential positive change in the provision of ESP courses in Burundi. For the change to happen, different stakeholders are involved - students, teachers, language departments and the government.

As far as students are concerned, this study might help them be aware of the reasons for learning English (getting access to academic and scientific sources published in English, increasing the chance to get a scholarship to study abroad, etc.). The more they get aware of these reasons, the much likely their motivation to learn English is to increase

Regarding teachers, the results of this study revealed that though many of the surveyed teachers are familiar with the practice of ESP, a few of them conduct a Needs analysis. This indicated that there is a need for teachers to reflect on the English courses they provide to NEM students. To put it differently, what ESP teachers in Burundi need to do is to first analyse the particular needs of students and then develop, adopt or adapt suitable materials that would cater for the needs of the students.

The findings of this study might also encourage the language departments to consider the issue of well preparedness of the teachers to teach English to special groups of learners. In other words, there is a need for language departments to enhance the teachers' ability to design, deliver and evaluate ESP programmes.

Given that $88.2 \%$ of the respondents reported they would highly encourage the ministry of education to fund an ESP project, the government of Burundi might feel this need and therefore initiate an ESP project that would help coordinate and support the teaching of English to special learners.

\section{Limitations for the study.}

Although this study revealed important findings, it does have some limitations. First, the number of respondents is low comparing to the targeted population (17 respondents out of 32). Had all the tertiary Burundi English teachers been willing to respond to the questionnaire, the study would have indicated much more reliable results. Second, this study did not involve students who constitute one of the key components in the teaching-learning process.

\section{Conclusion and Recommendations}

This study set out to investigate tertiary English teachers' views on the need for ESP 
in Burundi and examine the extent to which they are familiar with the theory and practice of ESP. Although many of the respondents reported to have, at least once, taught English in DBOE, many of them ignore the practice of NA, a key essence in ESP. Despite this, a great majority of the teachers recognize the importance of teaching English to NEM students and suggested that those students be taught both academic and vocational English. They also reported that they would highly encourage the Ministry of Education to fund an ESP project.

Given the above findings of this study, it is recommended to teachers to read more about ESP to get a comprehensive understanding of this field so as to fully serve the specific English language needs of NEM students. To the Ministry of Higher Education and Scientific Research, it is recommended to set up an ESP project which would help teachers of English to easily shift from General English teachers to ESP teachers and would therefore help coordinate the teaching of ESP in Burundi.

\section{References}

Alsubaie, S. (2016). ESP in Saudi Arabia: A Need for Active Community. International Journal of Language and Linguistics, 3(5), 107-111.

Basturkmen, H. (2017). ESP teacher education needs. Language Teaching, 51 (1), 1-13.

Basturkmen, H. (2010). Developing Courses in English for Specific Purposes. New York: Palgrave Macmillan.

Belcher, D. (2009). What ESP is and can be: An introduction. In D. Belcher (Ed.),
English for specific purposes in

theory and practice (pp.1-20).

Michigan: University of Michigan Press.

Bouyakoub, N., \& Bouyacoub, M. C. (2017). The ESP Teaching and Learning Situation in the A 1 g e $r$ i a $n$ Universities with Reference to Psychology Students at Tlemcen University. International Journal of Curriculum and Instruction, 9(2), 217227.

Brown, J. D. (2016). Introducing Needs Analysis and English for Specific Purposes. New York: Routledge.

Çelik, S., Stavicka, A., \& Odina, I. (2018).Are we really teaching English for specific purposes, or Basic English skills? The cases of Turkey and Latvia.In Y. Kýrkgöz \& K. Dikilitap (Eds.), Key issues in English for specific purposes in higher education (pp. 243-264). Cham: Springer International Publishing.

Dearden, J. (2018). The changing roles of EMI academics and English language specialists.In Y. Kýrkgöz \& K. Dikilitap (Eds.), Key issues in English for specific purposes inhigher education (pp. 323338). Cham: Springer International Publishing.

Dudley-Evans, T., \& St John, M. J. (1998). Developments in English for specific purposes: Amulti-disciplinary approach. Cambridge: Cambridge University Press.

Hutchinson, T., \& Waters, A. (1987). English for specific purposes. Cambridge: Cambridge University Press. 
Labassi, T. (2010). Two ESP projects under the test of time: The case of Brazil and Tunisia. English for Specific Purposes, 29(1), 19-29.

Lin, C. H., Wu, W. C., \& Huang, Y. T. (2013).English for specific purposes (ESP) for hospitality college students and hotel employees in Taiwan. International Journal of Education and Research, 1(8), 1-14.

Marlina, R., \& Xu, Z. (2018). English as a lingua franca. In J. I. Liontas (Ed.), The TESOL Encyclopedia of English Language Teaching (pp. 1-13). USA: John Wiley \& Sons.

Nizonkiza, D. (2006, March 23). English in Burundi: A non-colonial heritage.TRANS. Internet-Zeitschrift für Kulturwissenschaften. Retrieved from http://www.inst.at/

$$
\mathrm{trans} / 16 \mathrm{Nr} / 03 \ldots 2 /
$$
nizonkiza16.htm

Plonski, P., Teferra, A., \& Brady, R. (2013, November). Why are more African countries adopting English as an official language? Paper presented at African Studies A s s o c i a t i o n Annual Conference, Baltimore, Maryland. Retrieved June12, 2018, from $\mathrm{h} \quad \mathrm{t} \quad \mathrm{t} \quad \mathrm{p}: / /$ www.booksforafrica.org/assets / documents/2013-ASA-ConferenceEnglish-La

nguage-in-Africa-PAPER.pdf

Rahman, M. (2015). English for Specific Purposes (ESP): A Holistic Review. Universal Journal of Educational Research, 3(1), 24-31.
Sabieh, C. (2018). English for Specific Purposes (ESP) Testing. In J. I. Liontas (Ed.), The TESOL Encyclopedia of English Language Teaching, (pp. 1419).USA: John Wiley \& Sons.

Uwimana, D. (2014, September 17). English is now official language of Burundi. Iwacu English News, Retrieved from https://goo.gl/hktAc4

\section{Contributor}

Arcade Nduwimana is currently a PhD scholar in Applied Linguistics at the University of Burundi. He also teaches at Ecole Normale Supérieure du Burundi. He has done his Masters in Applied Linguistics and ESP and Bachelors in English Language and Literature at Kasdi Merbah UniversityOuargla in Algeria. His area of interest is ESP. 